\title{
REPRESENTAÇÕES SOCIAIS SOBRE EDUCAÇÃO AMBIENTAL E OBJETIVAÇÕES EM PRÁTICAS PEDAGÓGICAS NO ENSINO FUNDAMENTAL
}

\author{
SOCIAL REPRESENTATIONS ON ENVIRONMENTAL EDUCATION AND \\ OBJECTIVES IN PEDAGOGICAL PRACTICES IN FUNDAMENTAL \\ EDUCATION
}

\author{
REPRESENTACIONES SOCIALES SOBRE EDUCACIÓN AMBIENTAL Y \\ OBJETIVAS EN PRÁCTICAS PEDAGÓGICAS EN LA ENSEÑANZA \\ FUNDAMENTAL
}

\author{
Adriana Maria Avila ${ }^{1}$ Edival Sebastião Teixeira ${ }^{2}$
}

\begin{abstract}
RESUMO
O artigo relata uma investigação desenvolvida na Rede Municipal de Ensino de São Lourenço do Oeste, Santa Catarina, cujos objetivos foram conhecer ações de Educação Ambiental desenvolvidas pelas professoras da rede; identificar suas representações sociais sobre Educação Ambiental e os modos pelos quais elas se objetivam. A metodologia caracterizou-se pela abordagem qualitativa. Os instrumentos de coleta de dados foram: um questionário de evocação livre, entrevista semiestruturada e pesquisa documental. Os dados resultantes do questionário de evocação livre foram analisados através da abordagem estrutural da Teoria das Representações Sociais. Os dados resultantes da entrevista e da leitura dos documentos orientaram-se pela Análise de Conteúdo. Os resultados obtidos sugerem que as participantes do estudo representam socialmente Educação Ambiental como um conjunto de práticas educativas que visam conscientizar para a preservação dos recursos naturais e capacitar o indivíduo a desenvolver atitudes sustentáveis.
\end{abstract}

PALAVRAS-CHAVE: Educação Ambiental. Representações Sociais. Práticas Pedagógicas.

\begin{abstract}
The article reports an investigation carried out in the Municipal Teaching Network of São Lourenço do Oeste, Santa Catarina, whose objectives were to know Environmental Education actions developed by the teachers of the network; Identify their social representations about Environmental Education and the ways in which they are objectified. The methodology was characterized by the qualitative approach. The instruments of data collection were: a questionnaire of free recall, semi-structured interview and documentary research. The data resulting from the free recall questionnaire were analyzed through the structural approach of the Theory of Social Representations. The data resulting from the interview and the reading of the documents were guided by Content Analysis. The results suggest that the participants of the study represent socially Environmental Education as a set of educational practices that aim to raise awareness for the preservation of natural resources and enable the individual to develop sustainable attitudes.
\end{abstract}

\footnotetext{
1 Mestra pelo Programa de Pós-Graduação em Desenvolvimento Regional da UTFPR. E-mail: avilaadri@hotmail.com.

${ }^{2}$ Doutor em Educação. Docente do Programa de Pós-graduação em Desenvolvimento Regional da UTFPR. E-mail: edival@utfpr.edu.br.
}

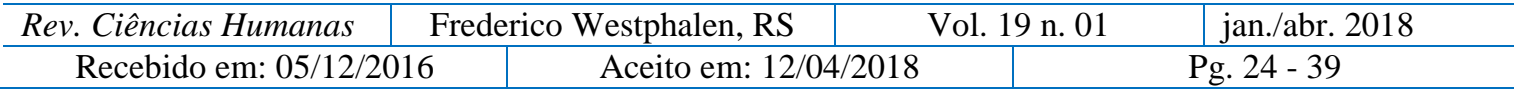




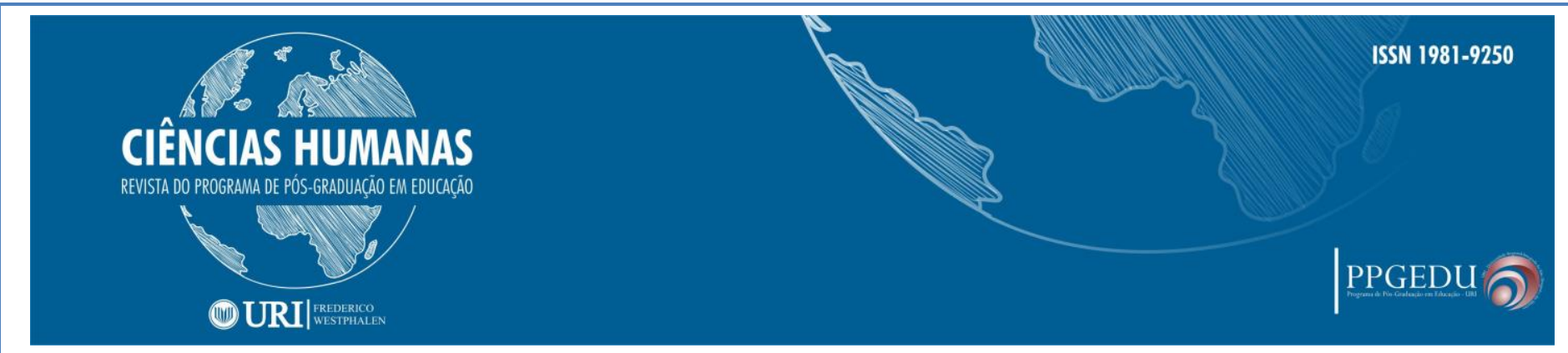

KEYWORDS: Environmental Education. Social Representations. Pedagogical practices.

\section{RESUMEN}

En este artículo se informa de una investigación desarrollada en la Red Municipal de Sao Lourenco do Oeste Educación, Santa Catalina, cuyos objetivos fueron conocer las acciones de educación ambiental desarrollado por los profesores de la red; identificar sus representaciones sociales de la educación ambiental y las formas en las que se destinan. La metodología se caracteriza por aproximación cualitativa. instrumentos de recolección de datos fueron: un cuestionario de investigación de evocación libre, entrevistas semiestructuradas y documental. Los datos del cuestionario de recuerdo libre se analizaron mediante el enfoque estructural de la Teoría de las Representaciones Sociales. Los datos de entrevistas y documentos de lectura guiada por el Análisis de Contenido. Los resultados sugieren que los participantes en el estudio representan socialmente Educación Ambiental como un conjunto de prácticas educativas dirigidas a aumentar la conciencia para la preservación de los recursos naturales y que la persona pueda desarrollar actitudes sostenibles.

PALABRAS CLAVE: Educación ambiental. Representaciones Sociales. Prácticas pedagógicas.

\section{CONSIDERAÇÕES INICIAIS}

Em 2012 a Rede Municipal de Ensino de São Lourenço do Oeste, Santa Catarina, passou por significativa ampliação através do processo de municipalização levado a execução pelo Governo do Estado de Santa Catarina, com a finalidade de outorgar aos municípios a oferta de Educação Infantil e Ensino Fundamental. Com isso, o número de escolas e consequentemente de alunos e professores da rede foi ampliado. Atualmente a rede municipal conta com 12 unidades escolares oferecendo ensino de Educação Infantil, para crianças a partir dos 1,5 anos de idade e Ensino Fundamental Anos Iniciais e Anos Finais para as faixas etárias de 06 a 14 anos.

A pesquisadora atua como professora dos Anos Iniciais do Ensino Fundamental em São Lourenço do Oeste, desde 1994. Assim, estando em contato direto com as grades curriculares dos diferentes níveis de ensino, tem observado a quase ausência de temáticas relacionadas ao meio ambiente e a Educação Ambiental (EA) nos ementários curriculares e total ausência dessas nos cursos de capacitação para docentes oferecidos pela rede municipal durante o ano letivo.

$\mathrm{O}$ que se tem de concreto relacionado à Educação Ambiental nas escolas municipais são projetos elaborados pela Secretaria de Educação Municipal e os conteúdos sobre meio ambiente apresentados em material didático fornecido por editora privada para a disciplina de Ciências Naturais, os quais são trabalhados em algumas \begin{tabular}{l|c|c|c}
\hline Rev. Ciências Humanas & Frederico Westphalen, RS & Vol. 19 n. 01 & jan./abr. 2018 \\
\hline
\end{tabular}

\begin{tabular}{l|l|l} 
Recebido em: 05/12/2016 & Aceito em: 12/04/2018 & Pg. 24 - 39
\end{tabular}




\section{CIÊNCIAS HUMANAS}

REVISTA DO PROGRAMA DE PÓS-GRADUAĞ̈O EM EDUCAĞ̄o

\section{(1) URI|}

aulas, em um determinado bimestre, ocorrendo, desta forma, apenas uma vez no ano letivo. Além da esfera escolar, também se pode citar que o "Projeto João de Barro" de responsabilidade social da Empresa Enele, de iniciativa privada em parceria com as escolas do município, visa abordar as temáticas de Ecologia e Educação Ambiental.

O município não possui sistematização legal de Educação Ambiental. Não obstante, ampara-se na Lei $\mathrm{n}^{\mathrm{o}} 13.558 / 2005$, do Estado de Santa Catarina, intitulada Políticas Para a Educação Ambiental de Santa Catarina que apesar de recente apresenta uma proposta para garantir que a Educação Ambiental esteja representada nos processos de ensino. Ademais, há ainda o Código Estadual de Meio Ambiente, Lei no 14.675, de 13 de abril de 2009, o qual se apresenta como um importante documento para a EA, mas supostamente conhecido e divulgado entre os educadores para ampliação dos conhecimentos relativos à Educação Ambiental.

Assim, observa-se que em São Lourenço do Oeste a Educação Ambiental está se fazendo presente nas escolas. Não obstante, a pesquisa ora relatada evidenciou que as ações de EA desenvolvidas atualmente nessa rede de ensino são incipientes, insuficientes, esporádicas e precárias; e que as práticas de EA desenvolvidas na rede relacionam-se diretamente com as representações sociais sobre Educação Ambiental dos respectivos professores, as quais, por sua vez enfatizam aspectos biogeoquímicos do ambiente em detrimento das relações entre tais aspectos e aspectos sociais e culturais.

$\mathrm{O}$ artigo ora apresentado relata pesquisa que teve por objetivo conhecer ações de Educação Ambiental desenvolvidas pelas professoras da rede; identificar suas representações sociais sobre Educação Ambiental e os modos pelos quais elas se objetivam.

\section{REFERENCIAL TEÓRICO}

A teoria das Representações Sociais tem sido amplamente utilizada pelas ciências sociais, por preconizar o fenômeno das representações sociais como uma forma complexa do ser humano organizar seu saber acerca do real, num movimento de construção que é ao mesmo tempo individual e coletivo. Por conseguinte, é pertinente a 


\section{CIÊNCIAS HUMANAS}

REVISTA DO PROGRAMA DE PÓS-GRADUAĞ̈O EM EDUCAĞ̄o

\section{(10) URI|}

utilização da Teoria das Representações Sociais como base teórica desse projeto de pesquisa tendo em vista seu caráter elucidativo frente ao papel das representações sociais do sujeito em suas relações cotidianas.

Para Moscovici (2009), as representações sociais consistem em um conjunto de valores, ideias e práticas que possibilitam às pessoas orientarem-se em seu mundo material e social e controlá-lo, bem como se comunicarem na medida em que fornece aos membros de determinada comunidade um conjunto de códigos que permitem classificar e nomear os vários aspectos da realidade individual e coletiva.

As representações sociais são construídas pelo sujeito através de suas experiências pessoais, de suas vivências históricas, de seu contato com o mundo real (MOSCOVICI, 2009). Porém, mesmo que as experiências vividas pareçam imprescindíveis para a construção das representações, quando estas estão vinculadas ao campo social, a comunicação exerce papel de propagação de representações muitas vezes arbitrárias, sem qualquer contato real por parte do sujeito que passará a representa-las mentalmente. Duveen (2009, p. 8), por sua vez, afirma que "as representações sustentadas pelas influências sociais da comunicação constituem a realidade de nossas vidas cotidianas e servem como o principal meio para estabelecer as associações com as quais nos ligamos uns aos outros". Assim, as influências sociais passam a integrar o conjunto das preocupações que nos afetam e, portanto, as partilhamos com os integrantes de nosso grupo social, constituindo-se como representações sociais.

Émile Durkheim, no século XX, apresentava a discussão da temática das representações coletivas, as quais, para esse autor, influem nas decisões individuais dos seres humanos. Em $O$ Suicídio, publicado em 1897, Durkheim descreve o ato do suicídio como sendo individual, com predisposições psíquicas, mas também com causas coletivas, originadas nas representações sociais do sujeito (REIGOTA, 2010). Tendo por base os trabalhos de Durkheim sobre as influências coletivas sobre o comportamento individual, Moscovici (2009, p. 49) amplia a discussão considerando que as representações sociais "são fenômenos específicos que estão relacionados com um modo particular de compreender e se comunicar - um modo que cria tanto a realidade quanto o senso comum". Isto é, Moscovici considera o papel determinante que 


\section{CIÊNCIAS HUMANAS}

REVISTA DO PROGRAMA DE PÓS-GRADUAĞ̈O EM EDUCAĞ̄o

\section{(1) URI|}

as representações sociais têm na construção do modo como as pessoas pensam e interagem no e com o mundo.

Desse modo a Teoria das Representações Sociais propõem que o conhecimento que se tem a cerca de um fenômeno sempre será uma construção com base em interações do sujeito com o que está sendo conhecido e claro que ao fazê-lo, reconstruirá este conhecimento imprimindo-lhe significações subjetivas, o que imprime também a essa representação um caráter social.

De acordo com Moscovici (2009) os processos cognitivos de ancoragem e de objetivação são os meios pelos quais os indivíduos inserem em seus quadros de referência o "novo", comparando-o e interpretando-o relativamente ao já familiar, o que permite, por sua vez, reproduzi-lo e controlá-lo.

A ancoragem é o processo por meio do qual o indivíduo suporta e transforma o desconhecido, reduzindo-o a categorias e imagens relacionadas a coisas que lhes são familiares. Isto é, a ancoragem "transforma algo perturbador, que nos intriga, em nosso sistema de categorias e o compara com um paradigma de uma categoria que nós pensamos ser apropriada" (MOSCOVICI, 2009, p. 61). Por essa razão, o autor em questão afirma que sua teoria não concebe a existência de um pensamento ou uma percepção que não possuam ancoragem, porque os sistemas de classificação e nomeação não são simplesmente meios para rotular ou graduar pessoas ou objetos.

A objetivação é o processo que torna concreto algo abstrato, como a transformação de uma ideia, um pensamento, em uma ação, em um ato de comportamento. Em outras palavras, o que é uma cognição, pelo processo da objetivação transforma-se em algo tangível; de uma cognição a um ato manifesto.

Portanto, a objetivação é o processo por meio do qual se une o não familiar com a realidade, tornando-se, dessa forma, esse não familiar em realidade. Assim, "percebida primeiramente como um universo puramente intelectual e remoto, a objetivação aparece, então, diante de nossos olhos, física e acessível. [...] objetivar é descobrir a qualidade icônica de uma ideia; é reproduzir um conceito em uma imagem" (MOSCOVICI, 2009, p. 72). 


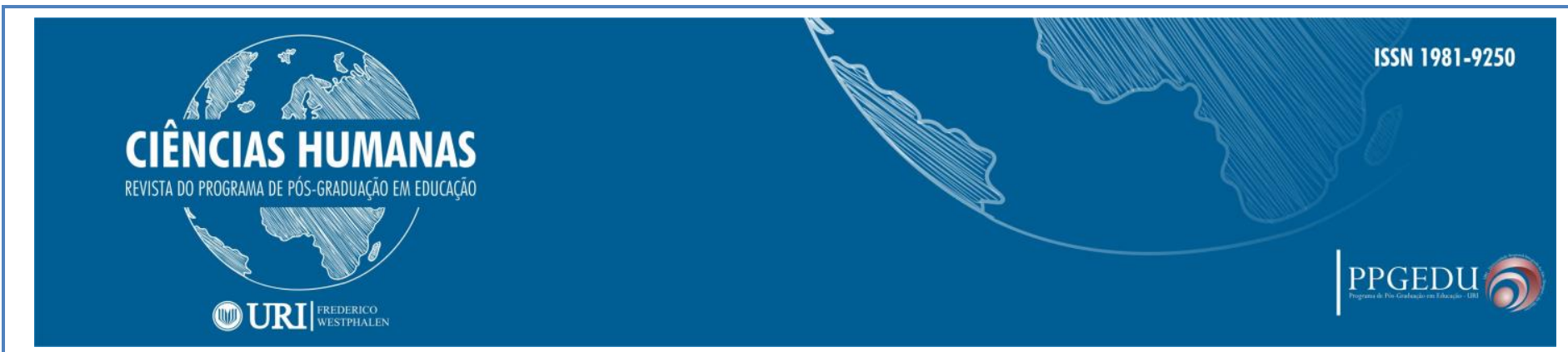

$\mathrm{Na}$ pesquisa em educação, a teoria das representações sociais tem sido bastante utilizada, em especial no tocante às relações entre representações e práticas pedagógicas, tais como nos estudos de Kus (2012) e Sander (2012). No que concerne à Educação Ambiental, Reigota (2010, p. 14) entende que "o primeiro passo para a realização da educação ambiental deve ser a identificação das representações das pessoas envolvidas no processo educativo". O autor faz essa afirmação mencionando o contexto de um curso de formação de educadores ambientais por ele ministrado na década de 1990. Na opinião de Reigota, ao se identificarem tais representações melhor podem ser programadas atividades de capacitação tendo em vista que as práticas pedagógicas são executadas conforme as concepções de mundo, de homem e de educação dos educadores. E as representações a que se refere o autor em questão são as de meio ambiente e de educação ambiental.

Com efeito, existem diversas concepções de Educação Ambiental. No Brasil, autores como Carvalho (2004), Loureiro (2004) e Guimarães (2007) afirmam a manifestação de duas tendências da Educação Ambiental: uma conservadora ou convencional - que seria hegemônica em nosso país - e a outra, transformadora ou crítica.

Loureiro (2004) e Guimarães (2007) apresentam a visão conservadora da prática pedagógica assinalando que a mesma se centra no indivíduo e em sua ação individual no meio ambiente. Trata-se de uma visão dualista da relação homem-natureza, separando em esferas distintas os sujeitos sociais a os elementos naturais.

Também Kus (2012) e Sander (2012) encontraram em seus estudos sobre as representações sociais sobre educação ambiental caraterísticas da visão conservadora nas práticas pedagógicas das professoras participantes da pesquisa. Tal visão faz com os educadores abordem em suas aulas temas ambientais sem vinculação com a realidade social, trata-se de uma interpretação abstrata e neutra da crise ambiental. Assim, os alunos por receberem um amontoado de informações desconexas, como por exemplo: dados sobre miséria e destruição do meio ambiente, orientações pontuais da destinação correta do lixo, a proteção das árvores, a economia de água, combate a poluição do ar, acabam por conceituar educação ambiental como um conjunto de informações ligadas 


\section{CIÊNCIAS HUMANAS}

REVISTA DO PROGRAMA DE PÓS-GRADUAĞ̈O EM EDUCAĞ̄o

\section{(1) URI|}

diretamente aos aspectos naturais da crise. Acríticos, não lhes é possibilitado pensar complexamente a crise ambiental.

Loureiro (2006) entende que a visão conservadora ignora a ação humana na esfera social negando, ao mesmo tempo, a historicidade e a práxis. O que resulta disso seria a ênfase numa ecologia descontextualizada dos problemas ambientais e assim, a luta pela proteção da natureza se sobressai como algo hierarquicamente prioritário sobre a luta por justiça e igualdade social, ao invés de ambas as coisas - a proteção da natureza a luta pela justiça - serem percebidas como intrinsecamente vinculadas.

Sendo a concepção de sujeito das pedagogias conservadoras - como Teixeira (2008) as define - a mesma da educação ambiental conservadora, a prática pedagógica nesta última, tal como nas primeiras, tende a localizar no indivíduo, senão a origem dos problemas ambientais pelo menos, grande parte da solução. Por essa razão, não questiona a forma de relação homem-natureza dualista, cartesiana, que separa em polos distintos a sociedade e a natureza, o sujeito e o objeto (LOUREIRO, 2004; GUIMARÃES, 2007). Da mesma forma, nunca problematiza as causas e as consequências sociais e econômicas da crise ambiental, as quais têm sua origem nas formas de relação engendradas pelo capitalismo (ANTUNES \& TEIXEIRA, 2011). Pelo contrário, ao limitar-se ao apelo para a sensibilização em relação à necessidade de preservar e conservar o ambiente mediante a utilização de práticas pontuais acaba despolitizando o debate e não estabelecendo qualquer relação entre a educação e a possibilidade de transformação da sociedade (GUIMARÃES, 2007).

Em se tratando da corrente crítica da educação ambiental são privilegiados os aspectos políticos que estão ligados à questão ambiental. Questionar o modelo econômico vigente é uma das características da vertente crítica de educação ambiental, considerando-se que dito modelo tem relação direta com a crise socioambiental. Guimarães (2007) assinala que ações "voltadas para as transformações da sociedade em direção à igualdade e à justiça social" (2007, p. 19), estão na base da proposta crítica de educação ambiental e se colocam como possibilidade de solução da crise ambiental.

Loureiro (2006) diz que o conhecimento é uma produção social e histórica, que, portanto, política e atendendo a interesses desses ou daqueles agentes sociais. Do 


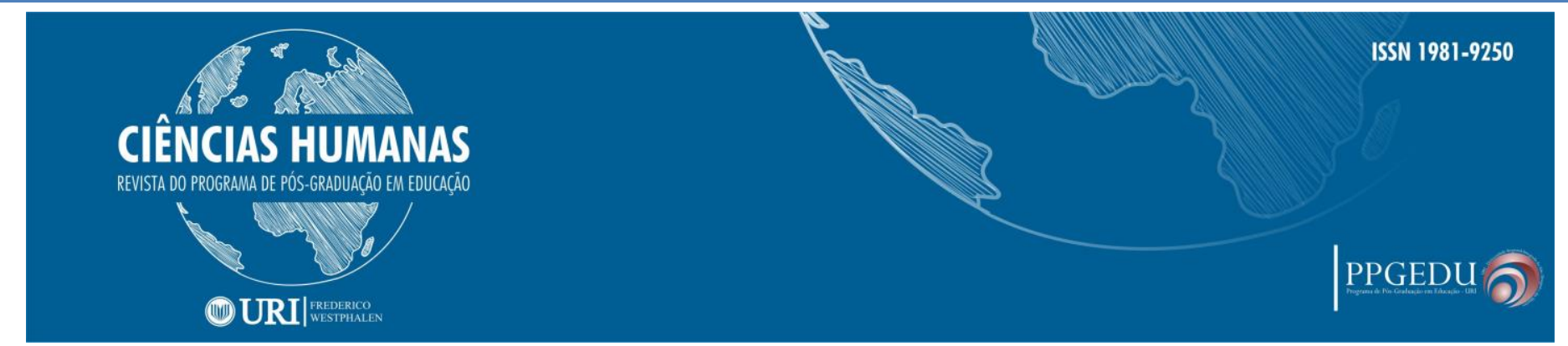

mesmo modo, a educação ambiental para a vertente crítica, é concebida como uma ação política, voltada a um fim, e dentre esses, a igualdade de condições de vida em sociedade a todos os cidadãos, condições essas de utilização e de preservação dos recursos naturais.

\section{PROCEDIMENTOS METODOLÓGICOS}

Participaram do estudo 36 educadores. A metodologia seguiu a abordagem qualitativa e os instrumentos de coleta de dados foram um questionário de evocação livre, entrevista semiestruturada e pesquisa documental.

Os dados obtidos do questionário de evocação livre foram analisados através da abordagem estrutural da Teoria das Representações Sociais.

O questionário continha uma questão de evocação livre, cujo termo indutor era Educação Ambiental e questões dissertativas nas quais as participantes eram solicitadas a justificar suas respostas.

O questionário foi aplicado durante visitas realizadas escolas da rede pública municipal onde as participantes professoras trabalhavam.

O material coletado com esse procedimento foi submetido ao programa Microsoft Excell® 2010 e análise foi realizada conforme os procedimentos para identificação do núcleo central das representações sociais descritos em Sá (1996) Teixeira e Algeri (2001).

As entrevistas foram realizadas nas residências das participantes, visto ocorrerem em janeiro, período das férias escolares. Para algumas entrevistas, a pesquisadora estabeleceu contato pelo telefone e agendou a visita e para outras, a pesquisadora optou por realizar a visita sem avisar antecipadamente. O instrumento continha três aspectos: a descrição de um dia típico de aula das participantes; o que as mesmas entendem por Educação Ambiental; suas práticas pedagógicas de Educação Ambiental.

Os documentos analisados foram: Matriz Curricular para o Ensino Fundamental de São Lourenço do Oeste - SC, Caderno V: Planejamento do Ensino Fundamental, Projeto Político Pedagógico 2014 e o Projeto Valores da Secretaria Municipal de Educação de SLO - SC. 


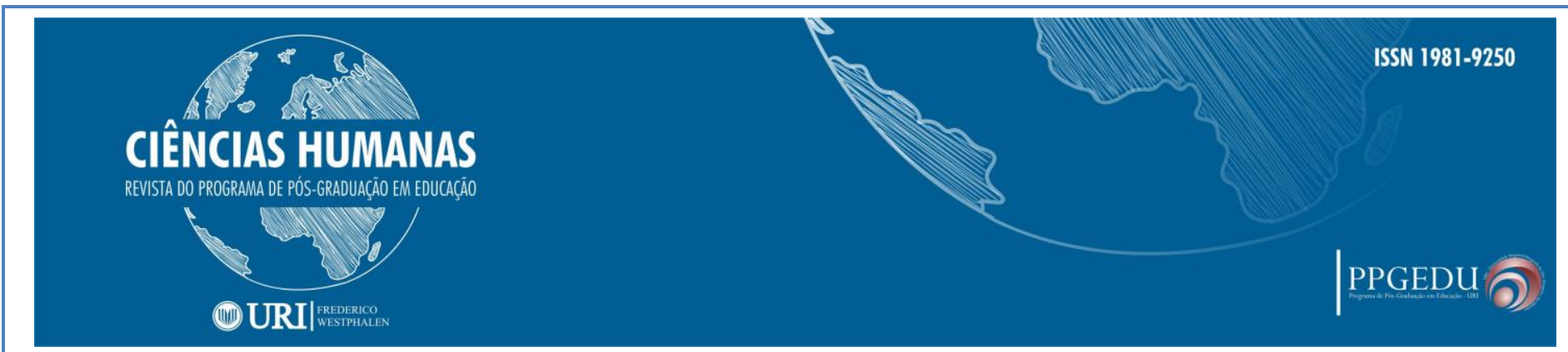

Os dados obtidos com a entrevista e com a análise de documentos foram submetidos à análise de conteúdo, conforme descrita por Franco (2008) e teve como prioridade a identificação de unidades temáticas.

Esses procedimentos de coleta de dados visando a identificação e análise de representações sociais têm sido utilizados com frequência em investigações na área, tais como nos recentes estudos de Vendruscolo et al (2013), Terossi e Santana (2013) e Teixeira e Algeri (2011). Sendo que principal base teórica do projeto consiste na Teoria das Representações Sociais de Serge Moscovici.

O projeto foi aprovado pelo Comitê de Ética em Pesquisa da Universidade Tecnológica Federal do Paraná, mediamente o Parecer nº 36614314.0.0000.5547.

\section{AS REPRESENTAÇÕES SOCIAIS SOBRE EDUCAÇÃO AMBIENTAL E AS PRÁTICAS PEDAGÓGICAS}

Os resultados obtidos permitem inferir que as representações sociais sobre Educação Ambiental das professoras pesquisadas é de que a mesma se constitui como um conjunto de práticas educativas visando conscientizar para a preservação dos bens naturais e capacitando o sujeito a desenvolver atitudes sustentáveis em relação à natureza.

Com efeito, o núcleo central dessas representações organiza-se em torno dos elementos conscientização, reciclagem, preservação, respeito, responsabilidade e educação. Esses elementos são os mais prontamente são lembrados pelas professoras evocados, bem como considerados pelas mesmas mais importantes que os demais elementos evocados mediante o termo indutor empregado.

Estes elementos estão presentes na pauta dos projetos e planejamentos pedagógicos levados a execução por essas professoras, conforme foi observado na análise realizada nos documentos da rede, bem como também estão explícitos nas suas falas como se exemplifica nos excertos de entrevista a seguir:

Existe uma falta de informação que permita identificar uma relação entre o que se faz na sala de aula e a Educação Ambiental. Poderia dizer que são práticas de reciclagem, economizar água e luz, cuidar do meio ambiente e reflorestar (Part. 2). 


\section{CIÊNCIAS HUMANAS}

REVISTA DO PROGRAMA DE PÓS-GRADUAĞ̈O EM EDUCAĞ̄o

\section{(1) URI|}

Educação Ambiental significa cuidar do nosso planeta (Part. 5).

É a conscientização sobre as questões ambientais, desenvolver atitudes sustentáveis, tentar preservar o que ainda temos (Part. 9).

Trata-se da importância do cuidado com a natureza. Devemos cuidar do meio ambiente para que no futuro tenhamos os recursos naturais para viver (Part. 16).

Conscientizar para que essas pequenas sementes deem bons frutos, desenvolvendo a Educação Ambiental de fato, com práticas corretas de Educação Ambiental (Part. 17).

Evidencia-se nesses fragmentos de falas que Educação Ambiental para as participantes da pesquisa significa conscientizar as crianças para cuidar da natureza. Nota-se que tal percepção por parte das professoras associa a ação do sujeito no meio ambiente como responsável direta pela sua preservação ou destruição. Nesse sentido, nota-se certa aproximação com a postura conservadora da Educação Ambiental, tal como também foi observado em pesquisas recentes como as de Kus (2012), Sander (2012) e Silva (2014).

As práticas de Educação Ambiental das professoras pesquisadas têm relação direta com o teor dos documentos pedagógicos e legais analisados. Por exemplo, o que está no Caderno V, que trata do planejamento para o E.F. I, no que tange as relações que o homem deve estabelecer com o meio ambiente, encontra-se também descrito na fala da Part. 3. Para essa participante o professor deve:

[...] se utilizar o tempo todo de ensinamentos dos modos corretos de se relacionar com o ambiente, motivando a criança a ter cuidado com o ambiente em que está inserida. Motivar a plantar árvores, por exemplo, é cuidar do meio ambiente (Part.3).

A preocupação da Participante 3 em ensinar a criança modos corretos de se relacionar com o ambiente demonstra a mesma visão do planejamento do Ensino Fundamental I. E quando ela afirma que ações como plantar árvore configuram o cuidado com o meio ambiente ela está propondo mudanças de atitudes e se mostrando fiel a sua representação social de Educação Ambiental. Esta visão também está presente na Lei n ${ }^{\circ} 9.795$ de 27 de abril de 1999, que institui a Política Nacional de Educação Ambiental, em seu Artigo $1^{\circ}$, onde se lê: 


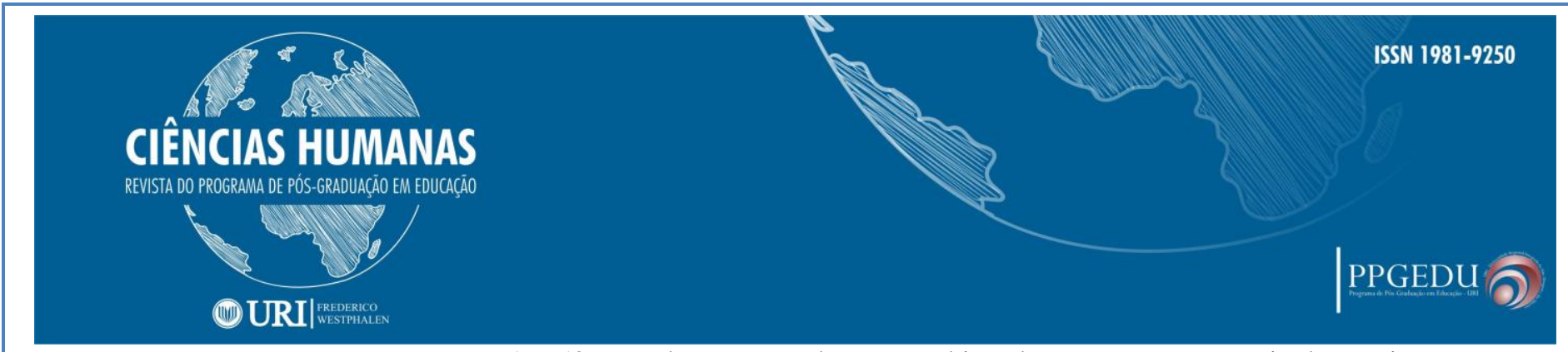

Art. $1^{\circ}$ Entendem-se por educação ambiental os processos por meio dos quais o indivíduo e a coletividade constroem valores sociais, conhecimentos, habilidades, atitudes e competências voltadas para a conservação do meio ambiente, bem de uso comum do povo, essencial à sadia qualidade de vida $\mathrm{e}$ sua sustentabilidade (BRASIL, 1999).

Do mesmo modo, o que se encontra registrado na fala da Participante 3 e na Política Nacional de Educação Ambiental, no que diz respeito a conservação do meio ambiente enquanto atitudes a serem ensinadas nas escolas e desenvolvida por cada um dos cidadãos; está também presente no Projeto Valores, desenvolvido pela Secretaria Municipal de Educação em parceria com todas as escolas do município. Trata-se de um projeto interdisciplinar, apresentando-se como uma temática transversal que agrega em seus objetivos a discussão sobre os valores éticos, morais e humanos na formação para a cidadania e para a conservação do meio ambiente.

Quando questionadas sobre as metodologias que poderiam ou que estão sendo usadas pelas professoras abordar a temática da Educação Ambiental, todas elas citaram práticas educativas que se destinam a formar indivíduos ambientalmente corretos.

As práticas de que falam as professoras foram agrupadas em práticas de preservação, que se observam em $88 \%$ das professoras pesquisadas e práticas devem desenvolver a responsabilidade individual para com a preservação e o cuidado com o planeta, em $77 \%$ da amostra.

No que diz respeito à preservação, lembramos que esse é um dos elementos que compõe o núcleo central das representações sociais sobre Educação Ambiental das professoras que lecionam no Ensino Fundamental I no município de São Lourenço do Oeste. As práticas pedagógicas desenvolvidas nesse sentido são exemplificadas, por exemplo, no depoimento da Participante 2, quando ela diz que Educação Ambiental "são práticas de reciclagem, economizar água e luz, cuidar do meio ambiente e reflorestar". E da Participante 13, ao dizer que EA: “[...] é um processo de conscientização que está em todo lugar, em casa, em pequenas ações, cuidados como economizar água, luz, promover a conscientização ambiental".

Podemos dizer que a visão de Educação Ambiental dessas professoras é a de que devemos preservar os recursos naturais. Essa mesma visão está manifesta na Carta de 


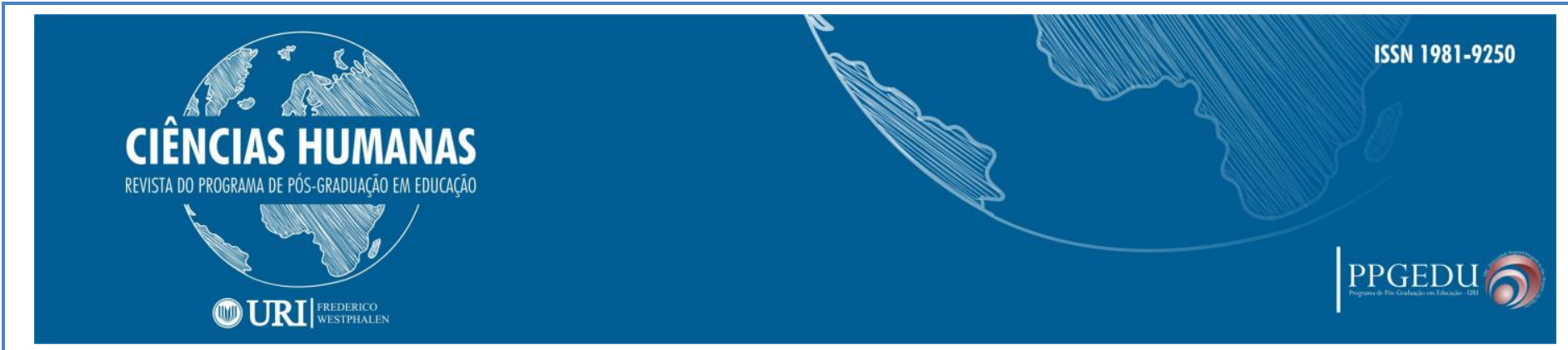

Belgrado de 1975, cujas metas são: "a preservação e a melhoria do meio ambiente no mundo" (SÃO PAULO, 1994, p.10). Nesse sentido, uma das professoras deixa notar a sua preocupação com a extinção dos recursos naturais e de como isso pode repercutir de modo desastroso para a vida humana. Trata-se da Participante 16 que diz: "hoje se o ser humano não tiver conscientização da importância da preservação, como será o futuro da nação?!”. Para ela, demonstrando uma visão antropocêntrica da relação sociedade e natureza, o "futuro da nação" estará comprometido na ausência da conscientização das crianças quanto a preservar a natureza. E essa é uma visão recorrente em pesquisas recentes como as de Kus (2012), Sander (2012) e Silva (2014).

Quanto a Educação Ambiental como práticas que devem desenvolver a responsabilidade individual para com a preservação e o cuidado com o planeta, a mesma tem a ver com o desenvolvimento da conscientização para preservação da natureza através de um conjunto de práticas individuais sustentáveis.

Um exemplo disso está na fala dessa participante:

Aprender a cuidar das árvores porque se você planta uma árvore você tem ar puro, água boa, assim é essencial cuidar das árvores, abrindo espaço para cuidado com reciclagem de lixo que muito importante (Part. 11).

A fala da Participante 11 aponta para uma visão naturalista, onde ações individuais de conservação, reciclagem e utilização consciente dos recursos naturais, renováveis ou não, darão conta de garantir o que a Participante 12 denomina “recuperação do planeta". Trata-se de uma postura preservacionista que ratifica a visão conservadora de Educação Ambiental.

Refletir sobre as transformações que devem ocorrer na relação homem-natureza, assinalando que a mesma está diretamente ligada a crise ambiental, requer primeiramente discutir a relação homem-homem dentro do modelo econômico-social capitalista. Acselrad, Mello e Bezzerra (2009) propõe que ao se afirmar a existência de uma crise ecológica com efeitos alarmantes, deve-se também afirmar que os maiores responsáveis são os seres humanos em seu processo civilizatório. 


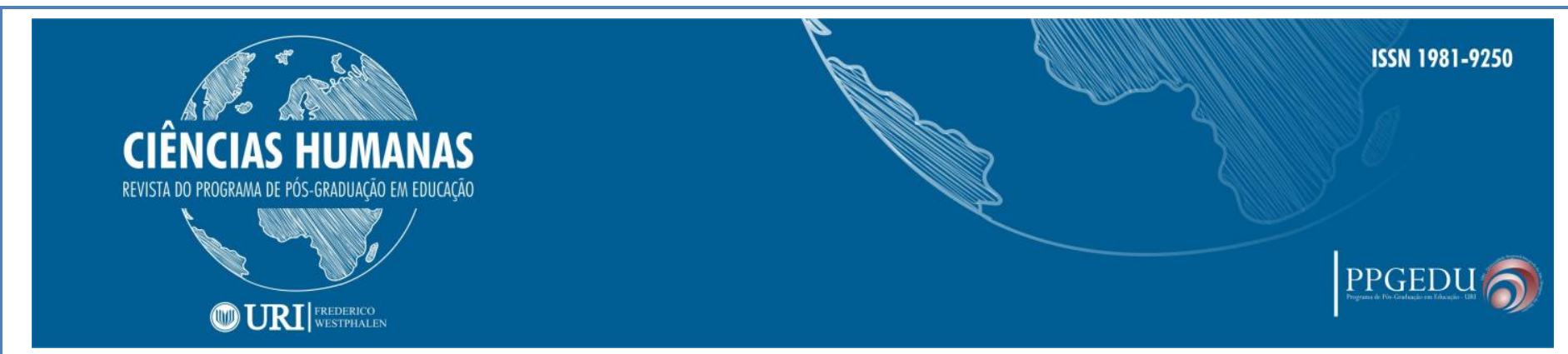

Ascelrad, Mello e Bezzerra (2009) apontam também para um novo conceito de meio ambiente, onde ele é considerado em sua totalidade, incluindo suas dimensões ecológicas, estruturais, sociais, políticas, estéticas e econômicas. Essa nova visão pode ser entendida como uma visão crítica da crise ambiental considerando-a resultante das ações antrópicas.

Para a abordagem crítica de EA a escola deve ser propulsora de ações que visem resolver os problemas gerados pelo atual modelo de desenvolvimento. Avila e Lingnau (2015, p.6) argumentam: "Não se pode pensar em uma análise complexa da problemática ambiental se não forem levados em conta nessa análise que os problemas do meio ambiente são também problemas do próprio desenvolvimento". Desse modo, a possibilidade de solução da crise ambiental implicará na busca por novas formas de organização social que promovam a igualdade de oportunidades e justiça ambiental a todos os sujeitos.

Guimarães (2001, p.51) esclarece que: "A compreensão adequada da crise pressupõe, portanto que esta diz respeito ao esgotamento de um estilo de desenvolvimento ecologicamente depredador, socialmente perverso, politicamente injusto, culturalmente alienado e eticamente repulsivo". Assim, o professor age criticamente quando é capaz de pensar a crise ambiental, conseguindo compreendê-la como resultado de um modelo de desenvolvimento consumista e degradador, tanto da natureza quanto do próprio homem.

Esse modelo de sociedade costuma homogeneizar o discurso sobre Educação Ambiental o que se traduz na tendência em atribuir a responsabilidade em solucionar os problemas ambientais a cada um dos sujeitos e aos seus comportamentos individuais de utilização sustentável dos bens naturais.

Em sentido inverso, quanto aos fins da Educação Ambiental, Suárez \& Marcote (2009, p. 90) escreveram: "ha de centrarse en las personas y en la comunidad y no en el medio; es decir, que en lugar de ser una educación a favor del medio, ha de ser una educacion para cambiar la sociedad". Uma sociedade com novos valores culturais e ambientais poderá agir coletivamente na construção de relações sustentáveis, com seus semelhantes e com a natureza. 


\section{CONSIDERAÇÕES FINAIS}

$\mathrm{Na}$ investigação realizada identificamos que as participantes do estudo representam socialmente Educação Ambiental como um conjunto de práticas educativas que visam conscientizar para a preservação dos recursos naturais e capacitar o indivíduo a desenvolver atitudes sustentáveis.

Essas representações de Educação Ambiental estão sendo objetivadas em suas práticas pedagógicas através de projetos de reciclagem e destino correto de lixo e outros resíduos tóxicos. Ou seja, práticas voltadas ao desenvolvimento da conscientização para a preservação da natureza. O conjunto de práticas pedagógicas descrito pelas professoras traduziu a representação dessas educadoras sobre Educação Ambiental. Representação essa que tem relação com o conteúdo dos documentos pedagógicos da rede, bem como nos documentos da política nacional de EA.

Percebemos que as participantes realizam práticas pedagógicas de EA relacionadas à abordagem conservadora de EA, o que está em consonância com a proposta de EA dos documentos da rede municipal de ensino de seu município. Ou seja, elas estão realizando seu trabalho apoiadas nas diretrizes educacionais propostas pela rede. E por sua vez, a rede está em consonância com a política nacional de EA.

Ao identificarmos a presença da visão conservadora de Educação Ambiental nos documentos pedagógicos da rede, se justifica em parte o porque de as participantes do estudo estarem realizando constantemente práticas pedagógicas de EA numa perspectiva naturalista/preservacionista que as impede de visualizar a amplitude do fenômeno socioambiental que se apresenta. Assim, a crítica não está nas Representações Sociais sobre Educação Ambiental, no trabalho dessas professoras ou nas diretrizes pedagógicas da rede. Ela está na visão de Educação Ambiental que está servindo de base para a elaboração dos documentos pedagógicos da rede, para a construção das representações sociais e para a objetivação dessas nas práticas pedagógicas de Educação Ambiental. 


\section{REFERÊNCIAS}

ACSELRAD, H; MELLO, C. C.A; BEZERRA, G. N. O que é justiça ambiental. Rio de Janeiro: Garamond, 2009.

ANTUNES, L. C., TEIXEIRA, E. S. Educação Ambiental e representação de meio ambiente em projeto pedagógico de escola municipal no sudoeste do Paraná. Synergismus scyentifica - UTFPR, n. 06 (1), 2011.

AVILA, A. M., LINGNAU, R. Crise ambiental, ensino de biologia e educação ambiental: uma abordagem crítica. Revista Monografias Ambientais Santa Maria, v. 14, n. 2, mai-ago. 2015 p. 137-150. Revista do Centro de Ciências Naturais e Exatas UFSM ISSN: 22361308.

BRASIL. Política Nacional de Educação Ambiental. Lei Federal n 9.795 de 27 de abril de 1999.

CARVALHO, I.C.M. Educação Ambiental Crítica: nomes e endereçamentos da educação. In: LAYARGUES, P.P. (Org.). Identidades da educação ambiental brasileira. Brasília: Ministério do Meio Ambiente, 2004, p.13-24.

DUVEEN, G. O poder das ideias. In: MOSCOVICI, S. Representações sociais: investigações em psicologia social. 7 ed. Petrópolis: Vozes, 2009, p. 7-28.

FRANCO, M.L.B.P. Análise de Conteúdo. 3 ed. Brasília: Líber Livro, 2008.

GUIMARÃES, M. Educação ambiental: no consenso um embate? 5 ed. São Paulo: Papirus, 2007.

GUIMARÃES, M. A formação de educadores ambientais. 8 ed. Campinas: Papirus, 2012.

KUS, H.J. Concepções de Meio Ambiente de Professores de Educação Básica e Práticas Pedagógicas em Educação Ambiental. (Dissertação de Mestrado) Programa de Pós-Graduação em Desenvolvimento Regional. Pato Branco: UTFPR, 2012.

LEFF, E. Saber ambiental: sustentabilidade, racionalidade, complexidade, poder. 5. ed. Petrópolis: Vozes, 2007.

LEFF, E. Epistemologia ambiental. 5a ed. São Paulo: Cortez, 2010. 


\section{CIÊNCIAS HUMANAS}

REVISTA DO PROGRAMA DE PÓS-GRADUAĞ̈O EM EDUCAĞ̄o

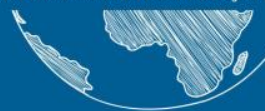

(1) URI|

LOUREIRO, C.F.B. Educação Ambiental Transformadora. In: LAYRARGUES, P. P. (Coord.). Identidades da Educação Ambiental brasileira. Brasília: Ministério do Meio Ambiente, 2004, p. 65-84.

LOUREIRO, C.F.B. Trajetórias e fundamentos da educação ambiental. 2 ed. São Paulo: Cortez, 2006.

MOSCOVICI, S. Representações sociais: investigações em psicologia social. 5 ed. Petrópolis: Vozes, 2009.

REIGOTA, M. Meio ambiente e representação social. 8 ed. São Paulo: Cortez, 2010.

SÁ, C.P. Núcleo Central das representações sociais. Petrópolis: Vozes, 1996.

SÃO PAULO. Coordenadoria de Educação Ambiental, Educação ambiental e desenvolvimento: documentos oficiais/ Secretaria do Meio Ambiente, Coordenadoria de Educação Ambiental. São Paulo: A Secretaria, 1994.

SANDER, L. Representações Sociais de Professores(as) a Respeito de Meio Ambiente e suas Práticas Pedagógicas Escolares em Educação Ambiental. (Dissertação de Mestrado) - Programa de Pós-Graduação em Desenvolvimento Regional. Pato Branco: UTFPR, 2012.

SILVA, L. F. Educação ambiental: representações sociais e práticas pedagógicas em cursos de formação de professores (Dissertação de Mestrado) - Programa de PósGraduação em Desenvolvimento Regional. Pato Branco: UTFPR, 2014.

SUÁREZ, P.A.; MARCOTE, P.V. Una propuesta educativa para la sostenibilidad. In: MIRA, R.G.; MARCOTE, P.V. (Directores). Sostenibilidad, valores y cultura ambiental. Madrid: Pirámide, 2009, p. 88-104.

TEIXEIRA, E.S. Ciclos de Aprendizagem: trajetória e fundamentos. Curitiba: Editora UTFPR, 2008.

TEIXEIRA, E.S.; ALGERI, F.L. Representações de Meio Ambiente e Educação Ambiental: um estudo com docentes de Casas Familiares Rurais. Práxis educativa (UEPG. Impresso), v. 6, p. 193-205, 2011.

TEROSSI, M.T.; SANTANA, L.C. Concepções e práticas de educação ambiental presentes nos projetos da Universidade Livre do Meio Ambiente (Umasq). Rev. Eletrônica Mestr. Educ. Ambient., v. 30, n.2, p. 64 - 84, jul./dez. 2013.

VENDRUSCOLO, G.S.; CONFORTIN, A.C.; MANICA, K.; ARESI, D. Concepção e práticas de professores sobre Educação Ambiental em escolas Públicas. Rev. Eletrônica Mestr. Educ. Ambient. V. 30, n.2, p. 49- 63, jul./dez. 2013.

\begin{tabular}{l|l|l|l}
\hline Rev. Ciências Humanas & Frederico Westphalen, RS & Vol. 19 n. 01 & jan./abr. 2018 \\
\hline
\end{tabular}

\begin{tabular}{l|l|l} 
Recebido em: 05/12/2016 & Aceito em: 12/04/2018 & Pg. 24 - 39
\end{tabular}

